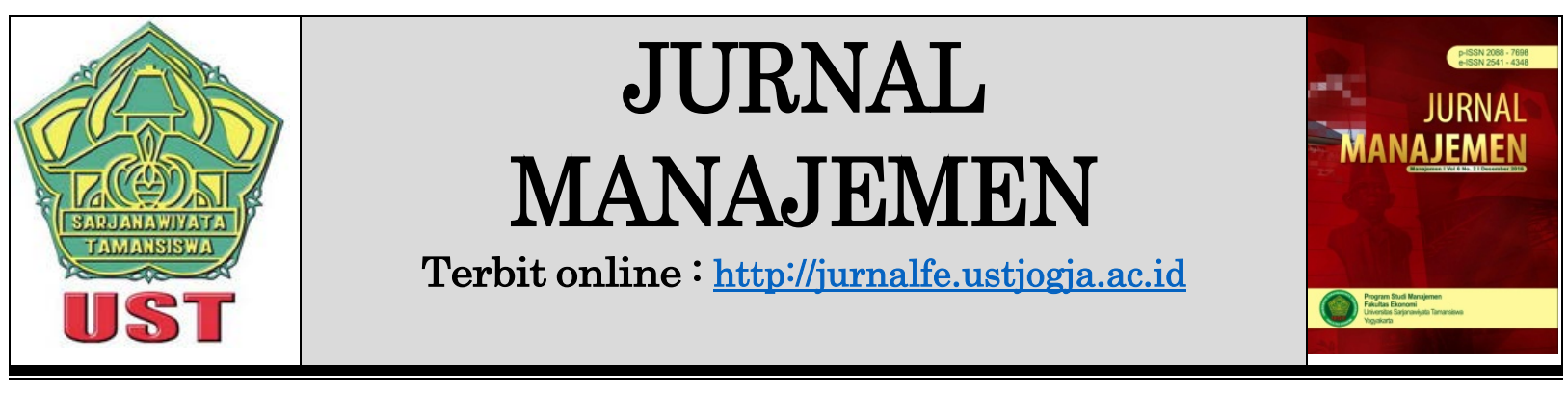

\title{
KEPEMILIKAN MANAGERIAL, RISIKO INTERNAL DAN EKSTERNAL, EFISIENSI DAN NET INTEREST MARGIN (NIM) DI BURSA EFEK INDONESIA
}

\author{
Ardian Prima Putra \\ Nurnaningsih
}

Universitas Veteran Bangun Nusantara Sukoharjo

Korespondensi: ardian.putura@gmail.com

\begin{tabular}{lc}
\hline Informasi Naskah & Abstrak \\
\hline Diterima: & This study aims to obtain empirical evidence of a \\
09 Oktober & number of factors that can affect the Bank's Net Interest \\
Revisi: & Margin (NIM) on the Indonesia Stock Exchange (IDX) in \\
11 Oktober & 2010-2016. The factors that are thought to influence NIM in \\
Terbit: & this study are managerial ownership, internal risk (non- \\
16 Desember & performing loans (NPL)), external risk (inflation), and \\
\hline Kata Kunci: & efficiency (operating expenses and operating income \\
Electronic Wallet, & (BOPO)). \\
TAM, Consumer & This research is expected to be beneficial for bank \\
Intention & shareholders in supervising and controlling bank \\
& management in managing NIM at the Bank, for management \\
& the bank can control the NIM at the bank, for the \\
& government to determine the bank's NIM policy \\
& appropriately, and for further research can add referrals in \\
& the field of banking research especially the NIM. \\
& This study uses multiple linear regression test, with the \\
& results simultaneously independent variables namely \\
& managerial ownership, non-performing loans, inflation, \\
& BOPO have a positive effect on Net interest Margin (NIM), \\
& while the partial test results ( $T$-test) is variable NPL, \\
& inflation has a negative influence on the net interest margin \\
(NIM) while the other variables do not have a bearing on the \\
NIM
\end{tabular}

\section{PENDAHULUAN}

Net interest margin (NIM) mencerminkan tingkat keuntungan bank dari pengelolaan aset. Keuntungan net interest margin didapatkan dari fungsi intermediasi perbankan yaitu sebagai lembaga penyalur dana dari pihak ketiga (debitur) kepada masyarakat (kreditur). Net interest margin merupakan keuntungan selisih dari bunga pinjaman (kredit) dan bunga simpanan (deposito). Menurut Chen dan Liao (2011) NIM adalah profitabilitas bagi bank. Sehingga NIM merupakan 
unsur penting bagi perbankan. Semakin tinggi NIM maka tingkat keuntungan yang didapatkan oleh bank juga semakin tinggi. Namun demikian, pemerintah Indonesia melalui Bank Indonesia akan membatasi tingkat bunga margin bank menjadi 4\%.

Pembatasan NIM tersebut berdasarkan data NIM perbankan di ASEAN adalah 2-4\%. Pemerintah Indonesia berharap bank nasional di Indonesia bisa bersaing dengan bank-bank di ASEAN. Disamping itu, pembatasan NIM juga untuk meringankan masyarakat Indonesia dalam hal pembebanan suku bunga kredit. NIM yang rendah dapat mengakses pasar lebih banyak bagi masyarakat Indonesia. Dengan kata lain, masyarakat lebih mudah mengakses kredit dengan suku bunga yang rendah.

NIM yang rendah juga mencerminkan tingkat efisiensi bank (Drakos, 2003; Beck dan Hesse, 2009; Lopez Espinosa dkk, 2011). Bank yang efisien dalam mengelola aset dapat menggunakan NIM yang rendah untuk mencapai profitabilitas. Tingkat efisiensi bank dapat diukur dengan perbandingan biaya operasional dan pendapatan operasional. Terdapat perbedaan hasil penelitian berkaitan dengan efisiensi bank dalam pengaruhnya terhadap NIM. Manurung (2012) dan Hawtrey dan Liang (2008) menemukan bahwa Biaya operasional (Efisiensi) dapat meningkatkan NIM. Maudos and Solis (2009) dan Irwan Trinugroho (2014) menemukan bahwa Cost to income ratio (CIR) dapat menurunkan NIM. CIR adalah faktor efisiensi perbankan.

Selanjutnya, kepemilikan pemerintah juga dapat mempengaruhi besarnya NIM bank. Micco (2007) mengatakan bahwa bank milik pemerintah memiliki kecenderungan tingkat margin bunga lebih tinggi. Namun Dracos (2003) mengatakan bahwa bank milik pemerintah di negara-negara Eropa Tengah dan timur (Central and Eastern European Countries (CEECs)) dan the Former Soviet Union countries (FSU), cenderung memiliki tingkat margin yang lebih rendah.

Sejumlah peneliti terdahulu baik dari luar negeri maupun Indonesia telah menemukan sejumlah faktor yang mempengaruhi NIM bank. Penelitian terdahulu menyebutkan bahwa Exchange rate dan Inflasi memiliki pengaruh signifikan terhadap NIM (Ikhide dan Yinusa, 2012, dan Ariefianto dan Soepomo, 2011). Sedangkan, Penelitian NIM di Indonesia menyebutkan bahwa NIM di Indonesia dipengaruhi oleh sejumlah faktor adalah Market power bank, risiko kredit, tingkat likuiditas bank, Size bank, efisiensi bank (cost to income), faktor spesifik bank, dan luasnya spread suku bunga. Selajutnya, juga ditemukan bahwa NIM perbankan di Indonesia cenderung tinggi (Sidabalok dan Viverita (2011), Manurung (2012) dan Trinugroho (2014)).

Berdasarkan hasil penelitian NIM terdahulu, faktor-faktor yang mempengaruhi NIM menunjukkan hasil yang berbeda. Hasil perbedaan ini menunjukkan masih adanya gap secara teori dan pengujian empiris. Selain itu, penelitian berkaitan dengan NIM menunjukkan jumlah yang terbatas bagi industri perbankan negara-negara di dunia. Demikian juga di Indonesia, penelitian NIM juga masih terbatas. Untuk itu, penulis tertarik untuk meneliti pengaruh Kepemilikan Manajerial, Risiko Internal dan Eksternal, Dan Efisiensi terhadap Net Interest Margin (NIM) di Bursa Efek Indonesia (BEI) tahun 2010-2016.

\section{KAJIAN PUSTAKA DAN HIPOTESIS Net Interest Margin}

NIM adalah ringkasan untuk mengukur return bunga bersih, komponen penting dari profit bank (Angbazo, 1997). Untuk mengidentifikasi akuntansi, margin bunga bersih bank (sebelum pajak) sama dengan profit ditambah biaya operasi bank, ditambah kerugian pinjaman, dikurangi pendapatan selain bunga (Demirguc-Kunt \& Huizinga, 2000). 
Kunt dkk (2003) menemukan bahwa net interest margin (NIM) dalam pinjaman tradisional dan pinjaman operasi bank mencerminkan efisiensi operasional murni dari bank dan lingkungan persaingan dari pasar perbankan. Ketidakefisien dan kondisi pasar cenderung meningkatkan biaya overhead daripada interest margin yang besar. Perbedaan diantara bank dalam interest margin mungkin mencerminkan pilihan apakah memilih biaya overhead yang tinggi atau margin yang besar daripada mencerminkan perbedaan efisiensi dan persaingan. Selanjutnya, margin bank mencerminkan alokasi aset dan tingkat risiko bank.

Tingginya NIM dapat diintepretasikan menjadi dua sudut pandang (Clayes dan Vennet, 2007). Pertama, tingginya NIM mencerminkan rendahnya tingkat efisiensi bank dan kondisi pasar perbankan yang tidak kompetitif. Kedua, tingginya interest margin mencerminkan ketidakcukupan peraturan perbankan dan tingginya asimetri informasi. Disamping itu, tingginya NIM juga mengindikasikan tingginya risiko premium, ketika kondisi persaingan meningkat maka akan mendorong perilaku spekulatif dari sistem perbankan yang dapat memimpin kestabilan keuangan (Hellman, Murdock dan Stiglitz, 2000).

\section{Kepemilikan Managerial}

Niskanen (2010) menemukan bahwa Kepemilikan managerial cenderung meningkatkan biaya agency (agency cost) sehingga menurunkan ketersediaan pinjaman, meningkatkan interest rate dan persyaratan pinjaman. Ho dan Saunders (1981) mengatakan bahwa menghindari risiko managerial yang lebih tinggi akan meningkatkan margin bunga.

\section{Non Performing Loan (NPL)}

Penelitian ini menggunakan NPL untuk mengukur kualitas kredit bank (Fungacova dan Poghosyan, 2011). Bank menghadapi risiko kredit yang lebih besar kemungkinan pengembalian risiko premium yang lebih tinggi dalam pinjaman mereka (Maudos dan De Guevara, 2004) dengan demikian meningkatkan margin bunga. Namun, disisi lain Fungacova dan Poghosyan (2011) mengatakan bahwa depositor mungkin mempersyaratkan rate bunga yang lebih tinggi dalam deposito mereka karena mereka merasa bahwa bank lebih berisiko dan oleh karena itu margin bunga dapat lebih rendah.

\section{Biaya Operasional Dan Pendapatan Operasional (BOPO)}

Biaya Operasional Dan Pendapatan Operasional (BOPO) adalah ukuran efisiensi bank. BOPO adalah prosentase perbandingan biaya dan pendapatan operasional bank. Manurung (2012) dan Hawtrey dan Liang (2008) menemukan bahwa Biaya operasional (Efisiensi) dapat meningkatkan NIM. Maudos and Solis (2009) menemukan bahwa Cost to income ratio (CIR) dapat menurunkan NIM. CIR adalah faktor efisiensi perbankan.

\section{Bank Size}

Bank Size merupakan ukuran bank dalam jumlah total aset yang dimiliki bank. Beck dan Hesse (2009) mengatakan bahwa bank yang semakin kecil dapat menghadapi biaya yang lebih tinggi dan mengatur margin yang lebih tinggi. Bank Size dapat diukur dengan Ln (total Aset).

\section{Inflasi}

Inflasi merupakan kenaikan harga-harga secara umum dan terus menerus sehingga meningkatkan harga pada barang lainnya (Bank Indonesia, 2007). Inflasi dapat juga diartikan sebagai kenaikan harga barang yang meluas. Indikator yang 
sering digunakan untuk mengukur tingkat inflasi adalah Indeks Harga Konsumen (IHK). Perubahan IHK dari waktu ke waktu menunjukkan pergerakan harga dari paket barang dan jasa yang dikonsumsi masyarakat.

\section{METODE PENELITIAN \\ Desain Penelitian}

Penelitian ini menggunakan metode kuantitatif. Metode kuantitatif adalah suatu metode penelitian yang dapat dihitung dengan jumlah satuan tertentu atau dinyatakan dengan angka-angka dengan menggunakan data sekunder (Sekaran, 2006 : 65). Penelitian ini merupakan penelitian hubungan sebab akibat yaitu pengaruh variabel independen terhadap variabel dependen.

Populasi, Sampel dan Teknik Sampling Penelitian

Populasi pada penelitian ini adalah bank konvensional baik BUMN maupun swasta yang terdapat di Bursa Efek Indonesia (BEI) tahun 2010-2016. Sedangkan, teknik pengambilan sampel menggunakan metode purposif sampling yaitu pemilihan sampel dengan tujuan tertentu, kriteria atau kuota tertentu (Sekaran, 2006 : 136). Data didapatkan dari Website Bank Indonesia, OJK, BEI, dan website bank.

\section{Definisi Operasional dan Pengukuran Variabel}

Net Interest Margin (NIM)

Net Interest Margin (NIM) adalah ukuran profitabilitas bank dari fungsi intermediasi bank yaitu menghimpun dana dan menyalurkan dana. NIM adalah selisih pendapatan bunga dan biaya bunga dibagi bunga laba aset. NIM diukur dengan skala desimal karena prosentase. Rumus NIM adalah sebagai berikut:

$\mathrm{NIM}=\underline{\text { Pendapatan Bunga }- \text { Biaya Bunga }}$

\section{Kepemilikan Managerial}

$$
\text { Bunga Laba Aset }
$$

Kepemilikan Managerial merupakan prosentase kepemilikan managerial pada suatu perbankan. Kepemilikan managerial dinyatakan dalam persen.

\section{Non Performing Loan (NPL)}

Non Performing Loan (NPL) adalah proksi dari ukuran kualitas pinjaman maupun tingkat kesehatan bank. Menurut surat edaran bank Indonesia No.6/23/DPNP/2004 rumus dari Non Performing Loans Gross yaitu sebagai berikut:

NPL gross $=\sum($ Pinjaman kurang lancar + diragukan + macet $)$

\section{Total Pinjaman}

Bank Indonesia mengatakan bahwa batas maksimal $5 \%$ untuk non performing loans bank. Jika melebihi angka tersebut maka mempengaruhi tingkat kesehatan bank tersebut.

Inflasi

Inflasi merupakan tingkat inflasi di suatu negara. Inflasi diukur dengan prosentase tingkat inflasi di Indonesia. Data inflasi diperoleh dari Bank Indonesia.

\section{Beban Operasional Dan Pendapatan Operasional (BOPO)}

Beban Operasional Dan Pendapatan Operasional (BOPO) adalah ukuran tingkat efisiensi bank. BOPO adalah jumlah perbandingan beban operasional dan pendapatan operasional bank. BOPO diukur dengan skala desimal karena berupa prosentase. Rumus BOPO adalah sebagai berikut:

\section{Bank Size}

$$
\mathrm{BOPO}=\underline{\text { Beban Operasional }}
$$

Bank Size merupakan ukuran seberapa besar aset yang dimiliki bank. Semakin besar total asset yang dimiliki bank maka bank tersebut menunjukkan bank yang besar. Bank Size diukur dengan LN Total Asset. 


\section{Teknik Analisis Data}

Bank Size $=$ LN (Total Asset)

\section{Analisis Regresi}

Teknik analisis data yang digunakan adalah analisis regresi berganda, karena variabel independen dalam penelitian ini berjumlah lebih dari satu. Teknik analisis regresi berganda merupakan teknik uji yang digunakan untuk mengetahui pengaruh variabel independen terhadap variabel dependen. Persamaan regresi linier berganda adalah

$\mathrm{Y}_{\mathrm{NIM}}=\alpha+\beta_{1} \mathrm{KM}+\beta_{2} \mathrm{NPL}+\beta_{3} \mathrm{INF}+\beta_{4} \mathrm{BOPO}+\beta_{5} \mathrm{Size}+\mathrm{e}$

\section{Keterangan :}

Y Nim $=$ Variabel Dependen Net Interest Margin

a $\quad=$ Konstanta

$B=$ Koefisien Variabel Independen

$\mathrm{KM} \quad=$ Kepemilikan Managerial

NPL $=$ Non Performing Loan

INF $=$ Inflasi

Size = Ukuran Bank

Exchange Rate $=$ Nilai tukar rupiah terhadap Dollar US

Inflasi $=$ Tingkat Inflasi di Indonesia

$\mathrm{e} \quad=$ eror

\section{HASIL DAN PEMBAHASAN}

Pada bagian ini menjelaskan hasil pengolahan data yang telah diperoleh. Data dalam penelitian ini adalah perusahaan perbankan yang terdaftar di Bursa Efek Indonesia (BEI). Data diperoleh dari laporan keuangan perusahaan perbankan tahun 2010-2016. Berdasarkan data yang diperoleh disajikan yang pertama adalah deskripsi data dan selanjutnya analisis multiple regression dengan uji $\mathrm{F}$ maupun uji t.

a. Statistik Deskriptif

Tabel 5.1 Statistic Descriptive

\begin{tabular}{|l|r|r|r|r|r|r|r|}
\hline & & & \multicolumn{2}{|c|}{} & \multicolumn{2}{c|}{$\begin{array}{c}\text { Std. } \\
\text { Deviation }\end{array}$} & Variance \\
\cline { 2 - 8 } & Statistic & \multicolumn{1}{|c|}{ Statistic } & \multicolumn{1}{c|}{ Statistic } & \multicolumn{1}{c|}{ Statistic } & Std. Error & Statistic & Statistic \\
\hline Inflasi & 154 &, 0302 &, 0838 &, 054514 &, 0017745 &, 0220216 &, 000 \\
\hline Bopo & 154 &, 3000 &, 9897 &, 789203 &, 0110363 &, 1369563 &, 019 \\
\hline Km & 154 &, 0000 &, 2040 &, 008324 &, 0026407 &, 0327706 &, 001 \\
\hline Size & 154 & 12,1445 & 29,9300 & 18,258456 &, 2040201 & 2,5318229 & 6,410 \\
\hline Nim & 154 &, 0102 &, 0960 &, 053227 &, 0013186 &, 0163633 &, 000 \\
\hline Npl & 154 &, 0021 &, 0890 &, 025520 &, 0012764 &, 0158392 &, 000 \\
\hline
\end{tabular}

Tabel 5.1 merupakan statistik deskriptif perusahaan Perbankan di BEI tahun 2010-2016. Variabel independen yang digunakan adalah NPL, inflasi, BOPO, Kepemilikan manajerial, dan Ukuran Perusahaan (SIZE) sedangkan variabel dependen adalah Net Interest Margin (NIM). Tabel 5.1 menyajikan nilai mean, minimum, maksimum, dan standar deviasi. 


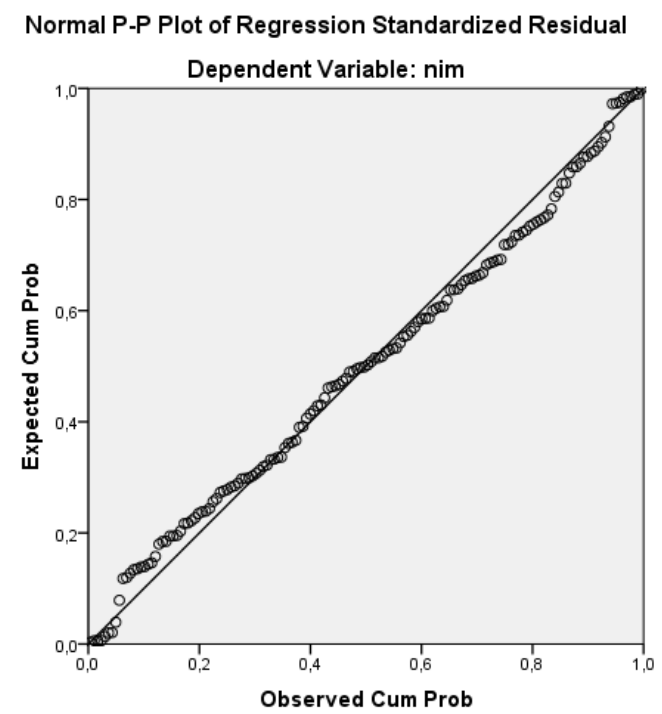

P-P Plot Normalitas Variabel NIM. Berdasarkan gambar diatas disepanjang garis diagonal sehingga data variabel NIM dalam observasi dapat dikatakan memenuhi asumsi normalitas.

Uji Multikolonieritas NIM

\begin{tabular}{|l|l|l|l|}
\hline Variabel & Tolerence & VIF & Keterangan \\
\hline NPL & 0,953 & 1,049 & Tidak terjadi Multikolonieritas \\
\hline Inflasi & 0,968 & 1,033 & Tidak terjadi Multikolonieritas \\
\hline BOPO & 0,904 & 1,106 & Tidak Terjadi Multikolonieritas \\
\hline KM & 0,918 & 1,089 & Tidak Terjadi multikolonieritas \\
\hline Size & 0,964 & 1,037 & Tidak Terjadi multikolonieritas \\
\hline
\end{tabular}

Uji Heterokedaktisitas NIM

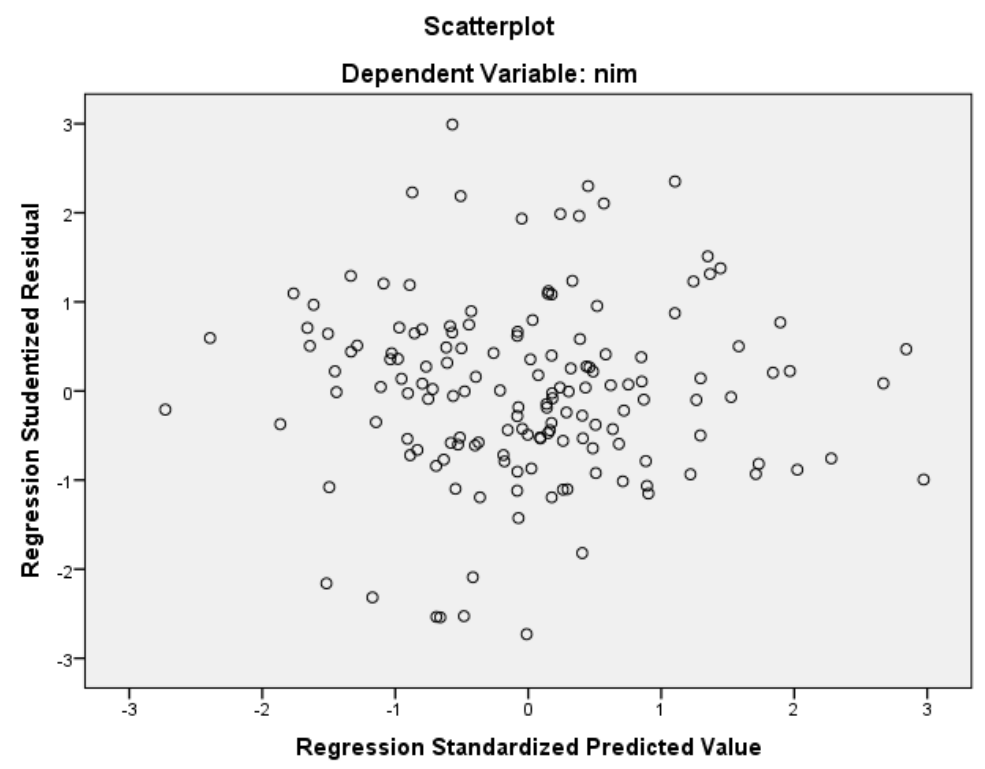

Berdasarkan Gambar diatas Scatterplot menyebar secara acak dan tidak berkumpul pada satu tempat, dengan demikian, data variabel NIM memenuhi uji asumsi Heteroskedatisitas. 
ANOVA $^{\mathrm{a}}$

\begin{tabular}{|c|c|c|c|c|c|c|}
\hline & & $\begin{array}{l}\text { Sum of } \\
\text { Squares }\end{array}$ & $\mathrm{df}$ & Mean Square & $\mathrm{F}$ & Sig. \\
\hline \multirow[t]{3}{*}{1} & Regression &, 005 & 5 & \multirow{3}{*}{$\begin{array}{l}, 001 \\
000\end{array}$} & \multirow[t]{3}{*}{4,224} & \multirow[t]{3}{*}{, $001^{b}$} \\
\hline & Residual & ,036 & 148 & & & \\
\hline & Total &, 041 & 153 & & & \\
\hline
\end{tabular}

a. Dependent Variable: nim

b. Predictors: (Constant), size, bopo, inflasi, npl, km

Uji $\mathrm{F}$ merupakan uji regresi untuk mengetahui pengaruh variabel secara simultan atau bersama -sama antara variabel independen dengan variabel dependen. Variabel -variabel dalam penelitian ini yaitu Non performing loan (NPL), infalsi, Rasio biaya operasional dan pendapatan operasional, kepemilikan manajerial, dan ukuran perusahaan. Hasil Uji F menunjukkan Nilai F hitung sebesar 4,224 dengan nilai signifikansi sebesar 0,001 hal ini lebih kecil dari nilai alpha sebesar 0,05 maka Variabel -variabel tersebut secara simultan berpengaruh positif terhadap Net Interest Margin.

\begin{tabular}{|c|c|c|c|c|c|c|c|c|}
\hline \multicolumn{9}{|c|}{ Coefficients $^{a}$} \\
\hline \multirow{2}{*}{\multicolumn{2}{|c|}{ Model }} & \multicolumn{2}{|c|}{$\begin{array}{c}\text { Unstandardized } \\
\text { Coefficients }\end{array}$} & \multirow{2}{*}{$\begin{array}{c}\begin{array}{c}\text { Standardi } \\
\text { zed } \\
\text { Coefficient } \\
\text { s }\end{array} \\
\\
\text { Beta } \\
\end{array}$} & \multirow[b]{2}{*}{$\mathrm{t}$} & \multirow[b]{2}{*}{ Sig. } & \multicolumn{2}{|c|}{$\begin{array}{c}\text { Collinearity } \\
\text { Statistics }\end{array}$} \\
\hline & & B & $\begin{array}{l}\text { Std. } \\
\text { Error }\end{array}$ & & & & $\begin{array}{c}\text { Toleran } \\
\text { ce }\end{array}$ & VIF \\
\hline & $\begin{array}{l}\text { (Consta } \\
\text { nt) }\end{array}$ & ,059 &, 013 & & 4,675 &, 000 & & \\
\hline & $\mathrm{npl}$ &,- 181 &, 081 &,- 175 & $-2,220$ &, 028 &, 953 & 1,049 \\
\hline & inflasi &,- 148 & ,058 &,- 199 & $-2,548$ & ,012 & ,968 & 1,033 \\
\hline & bopo &,- 016 &, 010 &,- 133 & $-1,645$ &, 102 & ,904 & 1,106 \\
\hline & $\mathrm{km}$ & ,038 & 040 &, 077 &, 961 & ,338 & ,918 & 1,089 \\
\hline & size &, 001 & ,001 & , 160 & 2,041 & ,043 & ,964 & 1,037 \\
\hline
\end{tabular}

a. Dependent Variable: nim

\section{PENUTUP}

a. Variabel NPL nilai signifikansi sebesar 0,028. Nilai signifikansi 0,028 merupakan nilai yang lebih kecil dari nilai signifikansi alpha 0,05 maka variabel NPL secara parsial berpengaruh negatif terhadap variabel NIM.

b. Variabel inflasi nilai signifikansi sebesar 0,012. Nilai signifikansi 0,012 merupakan nilai yang lebih kecil dari nilai signifikansi alpha 0,05 maka variabel inflasi secara parsial berpengaruh negatif terhadap variabel NIM

c. Variabel rasio beban operasional dan pendapatan operasional memiliki nilai signifikansi 0,102. Nilai signifikansi 0,102 merupakan nilai yang lebih besar dari nilai signifikansi alpha 0,05 maka variabel rasio beban operasional dan pendapatan operasional secara parsial tidak berpengaruh terhadap variabel NIM

d. Variabel Kepemilikan managerial nilai signifikansi sebesar 0,338. Nilai signifikansi 0,338 merupakan nilai yang lebih besar dari nilai signifikansi alpha 0,05 maka variabel kepemilikan manajerial secara parsial tidak berpengaruh terhadap NIM. 
e. Variabel ukuran perusahaan memiliki nilai signifikansi sebesar 0,043. Nilai signifikansi 0,043 merupakan nilai yang lebih kecil dari nilai signifikansi alpha 0,05 maka variabel ukuran perusahaan secara parsial berpengaruh positif terhadap NIM.

\section{REFERENSI}

Angbazo, L. 1997. Commercial Bank Net Interest Margin, Default Risk, Interest Rate Risk and Offbalance sheet Banking. Journal of Banking and Finance 21, 55-87.

Ariefianto, Moch Doddy dan Soepomo, Soenartomo. 2011. General and specific behavior of interest margin: evidence from post crisis Indonesian Banking. Journal of Arts, Science \& Commerce. E-ISSN 2229-4686. ISSN 2231-4172

Aydogan, Kursat dan Geoffrey. 1996. Performance characteristics of private and state-owned banks: The Turkish case. Managerial Finance. 22, 10; ABI/INFORM Research pg. 18

Claeys, S., Vennet, R.V., 2008. Determinants of bank interest margins in Central and Eastern Europe: a comparison with the West. Econ. Syst. 32, 197-216.

Drakos, K., 2003. Assessing the success of reform in transition banking 10 years later: an interest margins analysis. J. Policy Model. 25, 309-317.

Dumicic, Mirna; Ridzak, Tomislav. 2013. Determinant of Bank Net Interest Margins In Central And Eastern Europe. Financial Theory And Practice. Vol 37 (I) 1-30

Fungá cová, Z., Poghosyan, T., 2011. Determinants of bank interest margins in Russia: does bank ownership matter? Econ. Syst.35, 481-495.

Gelos, R. Gaston, "Banking Spreads in Latin America," IMF Working Paper, 2006, WP/06/44.

Ho, T., Saunders, A., 1981. The determinants of bank interest margins: theory and empirical evidence. J. Financial Quant. Anal. 16,581-600.

Honohan, Patrick, "Financial Development, Growth and Poverty: How Close Are the Links?" In Charles Goodhart, ed. Financial Development and Economic Growth: Explaining the Links. 2004, London: Palgrave.

Ikhide, Sylvanus dan Yinusa, Olalekan. 2012. Why is the cost of financial intermediation rising in botswana?. The Journal Developing Area,Volume 46 , No. 1 Spring 2012.

Kunt, A. Demirgiiu; Laeven, Luc; Levine, Ross. 2003. The Impact of Bank Regulations, Concentration, and Institutions on Bank Margins. Policy Research Working Paper 3030.

Manurung, A.Haymans. 2012. Net Interest Margin: Bank Publik di Indonesia.

Maudos, J., de Guevara, J.F., 2004. Factors explaining the interest margin in the banking sectors of the European Union. J. Bank. Finance 28, 2259-2281.

Maudos, J., Solís, L., 2009. The determinants of net interest income in the Mexican banking system: an integrated model. J. Bank. Finance 33, 1920-1931.

Micco, A., Panizza, U., Yanez, M., 2007. Bank ownership and performance. Does politics matter? J. Bank. Finance 31, 219-241.

Niskanen, Mervi;Niskanen, Jyrki. 2010. Small Business Borrowing and the OwnerManager Agency Costs: Evidence on Finish Data. Journal of Small Business Management; Jan 2010; 48, 1; ABI/INFORM Research pg. 16

Poghosyan, T., 2010. Re-examining the impact of in emerging markets. Emerg. Markets Rev. 11, 390-403.

Sidabalok, L. R. and Viverita (2011); The Determinants of Banks' Net Interest Margin in Indonesia: A Dynamic Approach; http://ssrn.com/abstract=1990175

Tarusa, Daniel K; Chekolb, Dan Mutwolc, Milcah. 2012. Determinants of Net Interest Margins of Commercial Banks in Kenya: A Panel Study. Procedia Economics and Finance 2 ( 2012 ) $199-208$ 
Trinugroho, I; Agusman, A; Tarazi, Amine. 2014. Why Net Interest Margin So High In Indonesia Since The 1997/1998 Financial Crisis. Research In International Business And Finance. Vol 32, 139-158.

Zhao dkk. 2014 . Introducing Foreign Strategic Investors And Net Interest Margins In Chinese Banks The Journal of Applied Business Research September/October 2014 Volume 30, Number 5 Copyright by author(s); CC-BY 1377 The Clute Institute 